\title{
Verbos de trajetória do PB: \\ uma descrição sintático-semântica
}

\author{
Verbs of path in BP: a syntactic-semantic approach
}

\author{
Rosimeire Corrêa \\ UFMG \\ Márcia Cançado \\ UFMG
}

\begin{abstract}
This paper presents a comprehensive syntactic/semantic analysis of the verbs of moviment in Brazilian Portuguese. We classify about 202 verbs that denotes a path, that is to say, verb that denotes a movement to one specific point to another. First, we classify the verbs according to their thematic properties. For that, we use Cançado (2003a, 2005) approach of thematic roles properties. That classification allows us to find six different classes of verbs of movement for BP. Each class presents specific syntactic and semantic properties. For syntactic properties, we analyze the displacement and the elimination of arguments. For semantic properties, we analyze the semantic meaning relation of the arguments and the akionsart of the analyzed sentences. We proposed here the difference between predicate locative and event locative. Also, we draw a general view of the syntactic and semantic differences between classes.
\end{abstract}

\section{Keywords}

verbs of path; argument structure; syntactic properties, semantic properties. 


\section{Resumo}

Este artigo apresenta uma ampla análise sintático-semântica dos verbos de movimento do português brasileiro (PB). Mais especificamente, classificamos 202 verbos que denotam trajetória, ou seja, verbos que acarretam um movimento de um ponto determinado para outro. Primeiramente, classificamos os verbos de acordo com as propriedades temáticas que eles apresentam. Para essa análise, usamos as propostas de Cançado (2003a, 2005) sobre propriedades dos papéis temáticos. Essa classificação nos levou a seis diferentes classes de verbos de trajetória para o PB. Cada classe apresenta propriedades sintáticas e semânticas específicas. As propriedades sintáticas analisadas foram deslocamento e apagamento de argumentos. As propriedades semânticas analisadas foram as relações de sentido entre os argumentos e as relações conhecidas como "aksionsart" (acionais) das sentenças investigadas. Propomos uma delimitação entre o locativo do predicador e o locativo do evento. E, ainda, traçamos um quadro comparativo entre as diferentes propriedades sintáticas e semânticas apresentadas pelas classes delimitadas.

\section{Palavras-chave}

verbos de trajetória; estrutura argumental; propriedades sintáticas; propriedades semânticas. 


\section{INTRODUÇÃO}

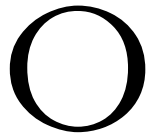

objetivo deste trabalho é mostrar uma análise descritiva sintáticosemântica dos verbos de movimento, especialmente os de trajetória, aplicando os pressupostos teóricos dos trabalhos de Cançado (2003a, 2005). Tratamos do corpus, relacionando as formas de coleta dos dados e a divisão dos mesmos em classes distintas. Exemplificamos alguns testes que serviram de suporte para algumas generalizações e, em seguida, fazemos a análise de cada classe, em particular.

O corpus, com 202 dados $^{1}$, foi formado a partir de consulta a dicionários da língua, conversa com falantes e dados de intuição. A pesquisa em dicionários privilegiou os verbos mais prototípicos e, muitas vezes, houve uma certa adequação à linguagem menos formal. Após o levantamento dos dados, foi feita uma distribuição dos verbos em classes distintas. Cada classe foi constituída de predicadores cujas propriedades apresentadas eram bastante semelhantes do ponto de vista sintático e semântico. Em cada sentença do conjunto de dados, foi levantada primeiramente a rede temática apresentada pelo predicador específico. Para corroborar o fato de que a rede temática apresentada realmente era específica àquela classe, foram aplicadas várias outras propriedades, sintáticas e semânticas, tentando evidenciar a natureza argumental dos papéis temáticos do predicador analisado. Como propriedades sintáticas, usamos o deslocamento e apagamento de argumentos; como propriedades semânticas, usamos substituições de itens lexicais de campos semânticos diferentes e foi feita a análise do aspecto (aksionsart) das sentenças. As conclusões e análises finais se deram a partir dos comportamentos apresentados pelos verbos de cada classe descrita. 


\section{A REDE TEMÁTICA}

Vejamos, primeiramente, quais foram os critérios para se estabelecer a rede temática das classes que serão apresentadas mais à frente. Segundo Cançado (2003a, 2005), a rede temática de cada verbo é estabelecida a partir das propriedades semânticas que compõem os papéis temáticos atribuídos aos argumentos desse verbo. Resumindo a proposta da autora, os argumentos de um predicador verbal são todos os termos acarretados lexicalmente por ele, ou seja, um predicador verbal pode ter três ou mais argumentos, dependendo do seu sentido. Essa proposta se diferencia do que se chama, geralmente, de argumentos na literatura em sintaxe; nessa perspectiva, argumentos são somente o sujeito e os complementos de um verbo (o que seria, no máximo, dois complementos). Para aplicarmos a noção de acarretamento, adotamos a definição de Dowty $(1989,1991)$, que diz o seguinte: acarretamento lexical é tudo que podemos concluir a respeito de um predicador somente por saber que $x$ predicador $y$ é verdade. Para exemplificar esse fato, tomemos como exemplo o item lexical colocar, na sentença expressa em (1):

(1) O professor colocou o livro na estante.

Temos, em (1), que o verbo colocar acarreta um desencadeador com controle: o professor; um afetado deslocado: o livro; e um locativo afetado: na estante. Se é verdade que o professor colocou o livro na estante, é verdadeiro afirmar que o ato de colocar foi desencadeado pelo argumento o professor; a afirmação de que o argumento o livro sofreu um deslocamento no espaço é verdadeira; e, finalmente, afirmar que o argumento na estante foi o ponto de chegada (ou alvo/ou destino) que é afetado pelo movimento é verdade. Ainda, segundo Cançado, os argumentos não são necessariamente explicitados na representação sintática. Para exemplificar esse fato, vejamos as sentenças em (2):

(2) a. Pedro veio de São Paulo para Belo Horizonte.

b. Pedro veio de São Paulo.

c. Pedro veio para Belo Horizonte.

d. Pedro veio. 
Em (2a), a sentença tem explicitados todos os argumentos do predicador vir, que acarreta um desencadeador deslocado, Pedro; e a trajetória representada pela origem, de São Paulo, e o destino, Belo Horizonte. O mesmo não ocorre nas sentenças em ( $2 b-d)$, nas quais há argumentos que não foram expressos sintaticamente. Em (2b), não aparece expresso o destino do movimento; em (2c), foi omitida origem do movimento; em (2d), a origem e o destino foram apagados. A sentença, em (2d), apesar de sintaticamente boa e bastante produtiva na língua, é uma sentença que necessita de um contexto mais amplo para não ter seu entendimento comprometido. Portanto, será essa noção de argumento que será utilizada para estabelecer a rede temática de cada verbo.

A cada argumento será associado um papel temático, composto por uma ou mais propriedades semânticas mais gerais. Retomemos, aqui, brevemente, as propriedades semânticas com as quais trabalhamos ao longo da pesquisa e alguns dos dados analisados.

\subsection{O Desencadeador}

A propriedade semântica de desencadeador é aquela que se aplica ao argumento que tem papel fundamental no ato de desenrolar a ação denotada pelo verbo. Se compararmos as sentenças expressas em (3), veremos como se dá essa distinção:

(3) a. João atravessou o rio de uma margem a outra.

b. $O$ copo caiu do armário.

Podemos observar, em (3a), que João é responsável pelo ato de atravessar o rio; diferentemente do que se pode depreender do papel desempenhado pelo argumento copo na sentença, em (3b). O copo não dá início ao processo de cair, pelo contrário, ele sofre o processo aí expresso. Então, temos que João é desencadeador, pois é ele que inicia o movimento de atravessar.

\subsection{Afetado}

Na distinção feita acima, já podemos vislumbrar o que vem a ser o afetado. Ao contrário do desencadeador, o afetado não exerce papel no 
desenrolar da ação verbal, ou seja, o afetado não tem poder de iniciar o processo expresso pelo verbo. $\mathrm{O}$ afetado é, como o próprio nome diz, aquele que sofre a ação verbal, ou melhor, o afetado muda de um estado A para um estado B. Mostraremos esse fato em (4):

(4) O mensageiro entregou as cartas à governanta.

Vemos, em (4), que o argumento as cartas muda de um estado A para um estado B, ou seja, num momento está com o mensageiro e, no outro, passa para a governanta.

\subsection{O Estativo}

O estativo refere-se ao argumento que não tem suas propriedades alteradas num determinado intervalo de tempo, ou seja, as propriedades do estativo continuam as mesmas em $t_{1}=t_{2}=t_{3}$. Observe a sentença, em (5):

(5) Maria centralizou o molde no tecido.

Em (5), temos que o argumento no tecido não tem suas propriedades alteradas no intervalo $t$, visto que no tecido já era o local em que o molde estava e, depois, foi deslocado para o centro. Ainda podemos acrescentar a propriedade locativo, pois no tecido é o lugar em que se dá o processo. Entretanto, nem todo locativo será atrelado ao estativo, pois um lugar também pode ser afetado, como mostra o exemplo 6.

(6) Maria atingiu a seta no alvo.

Temos, em (6), um locativo que é afetado pelo processo. Aqui neste trabalho, faremos, então, essa divisão na tentativa de estabelecer uma rede temática mais fina para os verbos estudados.

\subsection{O Controle}

O controle é uma propriedade compatível com qualquer uma das outras três. Esta propriedade refere-se ao fato de se poder interromper a ação, processo ou estado expressos pelo verbo. Veja o exemplo em (7): 
(7) a. O jardineiro não vai mais ajuntar a terra num canto.

b. O jardineiro não vai mais morar aqui.

Observe que, em (7), o jardineiro tem o controle sobre o ato de ajuntar ou o estado de morar, ou seja, ele pode interromper a ação verbal ou o estado.

\section{EVIDÊNCIAS DA NATUREZA ARGUMENTAL DAS REDES TEMÁTICAS APRESENTADAS}

Como a divisão das classes se deu a partir da rede temática apresentada pelos verbos, fez-se necessário a comprovação de que os papéis temáticos apresentados em cada classe tivessem realmente um status de argumento do predicador analisado. Para isso, usamos vários testes, sintáticos e semânticos, o que também evidenciou mais a organização das classes da maneira proposta pelo trabalho.

\subsection{As Propriedades Sintáticas}

Os procedimentos sintáticos explorados neste trabalho são as propriedades de apagamento e deslocamento de argumentos. Os testes utilizados nesta pesquisa, alguns também muito utilizados na literatura, não são, evidentemente, infalíveis; porém, proporciona-nos uma boa visão do comportamento desses dados, permitindo-nos assumir uma generalização confiável em nossas análises.

O primeiro teste, o de apagamento de argumentos, consiste em se omitir um ou mais argumentos de uma sentença e relacionar essas ocorrências à gramaticalidade e à aceitabilidade das sentenças. Esse teste tem como objetivo evidenciar a natureza de argumento dos termos em questão, assumindo-os ou não como participantes da rede temática daquele verbo específico. Veja os exemplos em (8):

(8) a. O professor colocou o livro na estante.

b. * O professor colocou o livro.

Em (8a), temos o verbo colocar que acarreta um desencadeador com controle, $O$ professor; um afetado e deslocado, o livro; e um locativo e 
afetado, na estante. Do ponto de vista semântico e sintático, a sentença, em (8a), é muito boa. Já a sentença, em (8b), não é aceita nem semântica nem sintaticamente. Segundo a literatura, parece-nos mais apropriada a aceitação de que o argumento apagado, que tem uma relação de sentido mais periférica na sentença, é o que se pode chamar de adjunto. Já o termo que não aparece na representação sintática, deixando anômala a sentença, é um argumento que tem uma relação de sentido mais nuclear com o verbo. Queremos deixar claro que esse teste não é infalível e gera muita controvérsia; entretanto, decidimos mantê-lo porque há classes em que o apagamento possibilita a classificação do termo omitido como um argumento.

Um segundo teste, também conhecido na literatura e que tem o mesmo objetivo do primeiro, ou seja, mostrar que o item lexical deslocado é argumento do verbo, é o teste de deslocamento de termos na sentença. Aplica-se o teste de deslocamento movendo um termo para o início da sentença. Parece-nos que um termo não acarretado pelo verbo, ou seja, o adjunto, pode ocupar essa posição mais livremente que um termo acarretado pelo verbo, ou seja, o argumento desse verbo. Observe as sentenças em (9):

(9) a. Os meninos subiram na árvore.

b. ?? Na árvore, os meninos subiram.

c. As mulheres predominam em $\mathrm{BH}$.

d. Em BH, as mulheres predominam.

A sentença em (9b) é menos aceita do que a sentença em (9d). Para que haja uma boa aceitação da sentença, em (9b), é necessária, no mínimo, uma entonação diferente. Como qualquer outro teste, esse também não é infalível; contudo, a maioria dos falantes prefere o deslocamento do locativo em (9d) ao deslocamento do locativo em (9b). Como em todas as classes dos verbos aqui tratados aparecem argumentos locativos, faz-se necessária uma melhor explicação para a distinção entre os locativos apresentados em (9b) e (9d).

\subsection{Locativo do Evento e Locativo do Predicador}

Partamos da observação de Franchi \& Cançado (1997, p. 132):

a expressão de lugar e tempo é irrestrita em qualquer oração, descreva ela ações, processo, estados ou evento que seja, ou a expressão de modo (como com capricho que foi utilizada em vários 
exemplos) é irrestrita em quaisquer orações que expressam uma ação, pelo que geralmente não faz sentido incluir etiquetas funcionais que expressem lugar, tempo, modo e outras similares, na diátese dos verbos. Entretanto, há casos em que papéis temáticos de tempo ou lugar devem ser inscritos como propriedades inerentes de verbos; é o caso de durar e começar. Essa questão depende de como se entende o conteúdo semântico desses papéis.

Concordando com a idéia exposta, parece-nos que é possível afirmar que existem dois tipos de locativos: um seria derivado do evento no mundo e o outro seria acarretado pelo predicador. Chamaremos o primeiro caso de locativo do evento e o segundo de locativo do predicador. O locativo do evento seria o lugar em que a ação ocorre, pois qualquer ação ou acontecimento ocupa obrigatoriamente um espaço no mundo. Observe as sentenças em (10):

(10) a. João cantou em BH.

b. João cantou num clube.

c. João cantou em cima da mesa.

d. João cantou em cima da mesa num clube em BH.

Em todas as sentenças em (10), há um locativo do evento, já que o item lexical cantar não acarreta necessariamente um argumento que indique o local. O que permite que se coloque um locativo é o ato de cantar, ou seja, quem canta pratica tal ação necessariamente em algum lugar. Tanto que esse locativo pode ser mais ou menos amplo; podemos comprovar isso com a gradação visível em (10a-d), em que o locativo de (10a) é mais amplo do que o de (10b), que é mais amplo do que o de (10c), e em (10d) os locativos expressos em (10a-c) coocorrem. Parece que, quanto mais amplo for o locativo, mais se nota a preferência de colocá-lo num ponto abaixo do locativo mais específico; apesar de que não seria tão mal dizer que João cantou em BH em cima da mesa. Mas, de qualquer forma, cantar não seleciona nenhum locativo como parte intrínseca de seu sentido, como podemos ver nas sentenças em (11):

(11) a. João cantou a noite toda.

b. João cantou muito bem.

c. João cantou. 
Em (11a-c), pode-se confirmar que as sentenças são boas e não há nenhum locativo. É óbvio que o evento só pode ter ocorrido em algum lugar, pois é impossível imaginar que algo aconteça no mundo sem que haja um espaço físico destinado a tal fato. Portanto, conclui-se que em BH, num clube e em cima da mesa são locativos do evento.

O segundo caso é locativo do predicador que é um argumento acarretado pelo verbo, ou seja, faz parte do sentido lexical do verbo. Veja, em (12), que o locativo do predicador é um argumento que tem um sentido mais específico e relacionado com o seu predicador e com os outros argumentos desse predicador:

(12) a. Maria imergiu o saquinho de chá na xícara.

b. Pedro sentou o filho na cadeira.

c. Maria recolheu a roupa do varal.

Entretanto, provar essa divisão não é uma questão simples. Muito se tem falado na literatura lingüística, e iremos propor algumas características que tentam evidenciar essa divisão. Um primeiro ponto, já conhecido e nem sempre infalível, é sobre a questão do apagamento de argumentos, descrito acima. O primeiro tipo de locativo, o locativo do evento, é mais geral e passível de apagamento sem perda de sentido. O segundo, o locativo do predicador, é mais específico e seu apagamento, em geral, traz problemas ao entendimento. Comprove nas sentenças, em (13):
a. Maria cantou em BH.
b. Maria cantou.

A sentença, em (13a), apresenta um locativo mais geral que estamos chamando de locativo do evento, ou seja, trata-se do lugar onde ocorreu o fato de Maria cantar. A sentença, em (13b), é amplamente aceita. $\mathrm{O}$ fato de se omitir o locativo em $B H$ não traz problemas em relação à compreensão da sentença, em (13b).

O apagamento do segundo tipo de locativo, o que chamamos de locativo do predicador, provoca danos ao sentido da sentença. Retomemos a sentença, em (12a), aqui, como (14a) e observemos o apagamento do seu locativo em (14b): 
(14) a. Maria imergiu o saquinho de chá na xícara.

b. ? Maria imergiu o saquinho de chá.

Não nos parece muito gramatical a sentença, em (14b). Essa sentença só seria aceitável se fizesse parte de um contexto mais específico. Portanto, isso seria um indício de que o locativo em (14a) é realmente um argumento do verbo e seu apagamento na estrutura sintática torna a sentença pouco aceitável.

Ao aplicarmos o teste do deslocamento dos argumentos, também vimos que o locativo do evento é mais livre, ou melhor, seu deslocamento não prejudica o entendimento da sentença. Comprove em (15):

(15) a. João leu um livro na biblioteca.

b. Na biblioteca, João leu um livro.

O mesmo não ocorre com o locativo do predicador, que é mais preso ao verbo. Observe esse fato em (16):

(16) a. O professor expulsou os alunos da sala.

b. ?? Da sala, o professor expulsou os alunos.

A aceitabilidade da sentença expressa em (16b) é bem menor que a da sentença, em (15b). Para que (16b) seja aceita sem restrições, é necessário que se aplique uma entonação diferente da que se usaria, por exemplo, no proferimento de (15b). Ainda, com uma entonação diferenciada, a sentença, em (16b) apresenta uma ambigüidade, porque o desencadeador, o professor, pode ter expulsado os alunos que estavam na sala, ou o professor é que estava na sala e, de lá, expulsou os alunos que estavam no pátio, por exemplo.

\subsection{As Propriedades Semânticas}

Ainda nos valemos de mais duas propriedades semânticas para comprovarmos a classificação dos verbos analisados: a substituição de termos relacionados a campos semânticos distintos e a análise do aspecto das sentenças (ou aksionsart, como também é conhecido esse tipo de análise semântica).

Um dos testes para estabelecer a diferença entre locativo do evento e locativo do predicador surgiu das nossas observações. Percebemos que uma 
das características que pode estabelecer a diferença entre o locativo do predicador e o locativo do evento é que o argumento locativo, acarretado pelo verbo, tem que pertencer ao mesmo campo semântico do verbo e de seu argumento interno; diferentemente do comportamento do locativo do evento. Quando usamos a expressão campo semântico, não pretendemos nos aprofundar nas várias teorias que abordam esse tema de uma maneira mais detalhada (ver CRYSTAL, 1988). Estamos assumindo, simplesmente, que campo semântico é um inventário de itens lexicais que estabelecem uma rede de relações de sentido. Um exemplo trivial dessa conceituação seria: o verbo falar se relaciona através de seu sentido com o nome língua, que por sua vez se relaciona com boca, que por sua vez se relaciona com falar, e assim por diante. Um nome como cadeira não faria parte do campo semântico acima estipulado, mas estaria em um outro campo semântico, estabelecido pelas palavras sentar, móveis, etc. Podemos, ainda, ilustrar essa definição de campo semântico, citando Crystal (1988, p. 41) que diz que "campo é um termo usado em semântica, com referência ao vocabulário de uma língua, quando ele é visto como um sistema de redes lexicais e não como um inventário de itens independentes".

Para demonstrar essa seleção de termos que têm certa compatibilidade semântica, foram aplicados testes de substituição do argumento locativo em vários dados coletados e o resultado foi que a sentença é menos aceita quando o campo semântico do argumento locativo não faz parte do campo semântico do verbo e do sintagma nominal que está na posição de argumento interno. Voltemos ao exemplo expresso em (12a), retomado, aqui, nas sentenças em (17):

(17) a. Maria imergiu o saquinho de chá na xícara.

b. ?? Maria imergiu o saquinho de chá na piscina.

c. ?? Maria imergiu o sapato na xícara.

d. ?? Maria imergiu o saquinho de chá em BH.

Todas as sentenças em (17) são gramaticais; porém, a aceitabilidade semântica das sentenças em (17b-d) é mais restrita. Na sentença, (17b), o locativo na piscina torna a sentença pouco aceitável, porque só podemos imaginar o evento como um acidente ou acontecimento parecido. Mesmo que na piscina se possa imergir alguma coisa, o campo semântico de 
saquinho de chá restringe tal colocação, visto que não se bebe chá diluído na água da piscina. Em (17c), o campo semântico de o sapato difere do de xícara, ainda que se possa imergir um sapato na piscina, por exemplo. Entender a sentença, em (17c), só é possível se partimos do conhecimento de que Maria esteja brincando ou fora de seu juízo perfeito. Em (17d), a expressão em $B H$ é um locativo que não pertence ao campo semântico de imergiu nem de saquinho de chá, pois, para se imergir algo, é necessário que se tenha um recipiente contendo líquido; e saquinho de chá seleciona preferencialmente xícara ou vasilha semelhante. Por conseguinte, (17d) pode ser considerada anômala do ponto de vista semântico. Parece-nos que a anomalia da sentença se deve ao fato de que em $B H$ não é um argumento pertencente ao campo semântico de saquinho de chá nem de imergir. Portanto, já que o locativo acarretado pelo predicador não apareceu na estrutura sintática, ela se mostra anômala. Já a sentença descrita em (17a) não nos causa nenhuma estranheza, pois os itens lexicais pertencem ao mesmo campo semântico e o predicador selecionou argumentos compatíveis com ele próprio e com seus argumentos.

Assim, faremos a distinção entre locativo do evento e locativo do predicador. Além de observarmos o deslocamento e o apagamento dos locativos dos predicadores, também examinaremos o critério de pertencer ao mesmo campo semântico.

Outra propriedade apresentada pelos verbos de movimento está relacionada às noções aspectuais das sentenças, conhecidas como aktionsart. Segundo Foltran (1999), Vendler (1967) apresenta quatro categorias aspectuais: os estados, as atividades, as sentenças que apresentam um accomplishment e as sentenças com achievements. Os estados se referem a ações que ocorrem por um determinado espaço de tempo:

(18) João amou Maria por três anos.

As atividades são constituídas de fases sucessivas:

(19) João corre todas as manhãs.

Os accomplishments são verbos que se desenrolam em direção a uma culminância, ou melhor, têm um início, um meio e um fim: 
(20) João correu de casa até a escola.

Os achievements denotam eventos de um momento único, ou melhor, ocorrem num momento definido:

\section{(21) João entrou na sala.}

Os verbos de movimento, aqui analisados, por acarretarem uma trajetória, explícita ou não na sintaxe, podem ser caracterizados por dois tipos aspectuais: os accomplishments e os achievements. Os do tipo accomplishment refletem a trajetória com princípio, meio e fim; os do tipo achievement só caracterizam um ponto da trajetória, geralmente o ponto final. Portanto, aplicaremos os testes propostos por Vendler (1967), para caracterizar as sentenças analisadas e poder classificá-las segundo as suas propriedades aspectuais.

Um dos testes consiste no acréscimo da expressão em x minutos. Tal acréscimo é perfeitamente aceitável com os accomplishments e barrado pelos achievements e atividades. Observe em (22):

(22) a. João correu da casa até a escola em duas horas.

b. * João entrou na sala em duas horas.

c. * João andava em duas horas.

Em (22a), temos um accomplishment, pois a ação expressa pelo verbo se desenvolve num período de tempo em que se tem o início, o meio e o fim do processo. Em (22b), temos um achievement, e a agramaticabilidade dessa sentença se deve ao fato de os achievements só ocorrerem num dado momento. Em (22c), temos uma atividade, que ocorre em momentos sucessivos, daí a agramaticalidade se demarcarmos um único momento.

Outro teste que distingue os accomplishments dos achievements é o uso da palavra quase. Veja em (23):

(23) a. João quase correu da casa até a escola.

b. João quase entrou na sala.

Observe que a sentença, em (23a), é ambígua, pois podemos pensar que João nem começou a correr ou parou antes de atingir o ponto final. Essa ambigüidade 
é característica dos verbos de accomplishment, porque os verbos de achievement não permitem dupla leitura. É o que podemos observar na sentença, em (23b): João não pode ter começado a entrar na sala, já que entrar é um verbo do tipo achievement, ou melhor, a ação expressa por ele é pontual, ocorre num momento único. Então, em (23b), a única leitura possível é a de que João não entrou na sala, ele apenas pensou em entrar e desistiu. Portanto, os verbos do tipo accomplishment apresentam duplicidade de sentido com o uso da palavra quase e os do tipo achievement só permitem uma leitura.

Esses testes e outros procedimentos similares serão exemplificados na análise dos dados da próxima seção.

\section{DESCRIÇÃO E ANÁLISE DAS CLASSES}

Depois de listados, os dados do corpus foram separados em classes de acordo com a rede temática apresentada, ou seja, conforme os argumentos acarretados pelo verbo. Os dados foram distribuídos em seis classes distintas. Cada classe foi descrita e analisada segundo as propriedades acima explicitadas. As classes 1 e 2 foram subdivididas em A e B, devido a apresentarem apenas diferença quanto ao deslocamento do argumento externo, sendo que os outros argumentos comportam-se de maneira idêntica. As demais classes apresentam redes temáticas distintas e, por isso, serão tratadas isoladamente.

\subsection{Classe 1: $A\{D(C), \quad A / D e s l, \quad \operatorname{Loc}(A)\}$ $B\{D(C) /$ Desl, A/Desl, Loc $(A)\}$}

(24) Eu entornei o açúcar na lata.

(25) O agricultor espalhou todas as sementes no terreno.

Como foi explicitado, a Classe 1 apresenta duas subclasses: A e B. A Classe 1-A contém verbos de movimento que acarretam um desencadeador (controle) $)^{2}$, um afetado/deslocado e um locativo (afetado) (exemplo (24)). A Classe 1-B é formada por verbos de movimento que acarretam um desencadeador/deslocado (controle), um afetado/deslocado e um locativo (afetado) (exemplo (25)). Portanto, os verbos da Classe 1-B se distinguem 
minimamente dos verbos da Classe 1-A por apresentarem um desencadeador/ deslocado. Como essa diferença não terá influência em nenhuma das propriedades analisadas, além do que, somente cinco exemplos aparecem nos dados da Classe 1-B, iremos tratá-las em conjunto. Fica a observação com o objetivo de se fazer uma análise mais fina dos papéis temáticos. Nessa classe, foram listados cento e três verbos mais prototípicos, sendo noventa e oito da Classe 1-A, e cinco da Classe 1-B; é a classe que apresenta mais exemplos.

Na Classe 1, temos apenas um dos pontos da trajetória representado sintaticamente. Como podemos observar na sentença, em (26):

(26) João afastou o filho do carro.

Em (26), temos que João é o desencadeador/controle; o filho é o afetado/ deslocado; e $o$ carro é o locativo/afetado, que, no exemplo, é o ponto inicial da trajetória. A trajetória descrita pelo predicador verbal está implícita, já que o ponto final do movimento não aparece expresso na representação sintática, embora seja acarretado pelo sentido do verbo, pois, ao ser deslocado, o afetado, o filho, irá ocupar um outro espaço físico diferente do anterior, $o$ carro. Assim sendo, apesar de acarretada pelo verbo, a trajetória - deslocamento de um ponto A para um ponto $\mathrm{B}$ - não está totalmente explícita na estrutura sintática. Tal fato ocorre com todos os dados da Classe 1.

Um tipo de comprovação dessa afirmação é que os verbos dessa classe são do tipo achievement, ou seja, o processo expresso pelo verbo é representado em um ponto único, ao contrário dos verbos do tipo accomplishment, que expressam o ponto inicial e final da trajetória. Para confirmar esse fato, vejamos os testes de achievement usados na literatura:

(27) a. O piloto aterrizou o avião no Galeão.

b. O piloto quase aterrizou o avião.

c. João quase atravessou o rio de uma margem a outra.

Na sentença expressa em (27a), temos o piloto no papel de desencadeador/ controle; o avião ocupa a posição de afetado/deslocado; e o Galeão representa o locativo/afetado. Para mostrar que os verbos desta classe são do tipo achievement, utilizamos a palavra quase que, nos accomplishments, possibilita uma dupla interpretação; e, nos achievements, permite uma só 
leitura. Portanto, o uso da palavra quase, em (27b), significa que o piloto não aterrizou o avião, pois não há como aterrizar pela metade; se, por outro lado, ele começou os procedimentos para aterrizar e desistiu, ele não aterrizou o avião. Para melhor explicitação desse fato, vejamos o que ocorre em (27c). Nesta sentença, João é o desencadeador/controle, o rio é o locativo/afetado e uma margem a outra é a trajetória. Quando acrescentamos o termo quase, estabelece-se uma ambigüidade: pode-se pensar que João nem começou a ação de atravessar o rio ou que ele parou em alguma parte da trajetória, sem, contudo, atingir o alvo. Como foi dito, somente os verbos do tipo accomplishment permitem essa dupla leitura, mostrando, portanto, que os verbos da classe 1 são do tipo achievement. A relevância dessa conclusão é que podemos afirmar que esses verbos, apesar de acarretarem uma trajetória, só expressam sintaticamente um ponto (final ou inicial) do processo e são, portanto, verbos do tipo achievement.

A Classe 1 mostra, também, que há uma divisão entre os locativos no sentido de serem ou não afetados. A literatura trata os locativos como sendo ligados aos estados, isto é, os argumentos não têm suas propriedades alteradas no intervalo $t$; entretanto, há locativos que são afetados pelo processo de movimento, quando há trajetória ou, ao menos, parte dela. Tomemos como exemplo as sentenças em (28):

(28) a. A costureira centralizou o molde no tecido.

b. O professor colocou o livro na mesa.

Em (28a), o desencadeador/controle é representado pelo item a costureira; o afetado/deslocado é o molde; e o locativo/estativo é tecido. Ainda em (28a), podemos verificar que o afetado (objeto deslocado) apenas muda de posição, ou melhor, o molde que, possivelmente, já está sobre o tecido, é movido mais para o centro. Assim sendo, o tecido não sofre alteração, permanece o mesmo em $\mathrm{t}_{1}, \mathrm{t}_{2} \ldots$, característica dos estativos, ou seja, o tecido já continha o molde que foi apenas levado para o centro. Em (28b), temos que o desencadeador/ controle é o professor; o afetado/deslocado é o livro; e o locativo/afetado é a mesa. Estamos chamando o locativo, em (28b), de afetado, pois, em dado momento, a mesa não continha o objeto deslocado e, em outro momento, sim. Nesse sentido, o locativo afetado se parece com o alvo ou destino da ação.

Entretanto, apareceram, também, dados em que o locativo afetado é semelhante à origem do movimento. Comprove na sentença, em (29): 
(29) Maria recolheu a roupa do varal.

Observe que na sentença, em (29), Maria é o desencadeador/controle; $a$ roupa é o afetado/deslocado; e $o$ varal é o locativo/afetado. Podemos notar que, em (29), o locativo/afetado, o varal, é o ponto inicial do movimento, isto é, sua origem. É fácil perceber a afetação nesse tipo de locativo, pois, em $\mathrm{t}_{1}$, o varal continha a roupa e, em $\mathrm{t}_{2}$, não.

Pode-se concluir, então, que a Classe 1 é constituída por verbos que ora selecionam locativos que denotam lugar, que não é afetado, ora selecionam locativos que são o ponto de origem (ou fonte) e/ou destino (ou alvo), que são afetados. Contudo, grande parte dos dados coletados apresenta o segundo tipo de locativo, ou melhor, parece que os verbos que admitem trajetória, mesmo que seja explícito só um ponto do movimento, acarretam locativos afetados. Essa análise não tem relevância para as propriedades estudadas, mas para uma análise mais fina, do ponto de vista descritivo semânticolexical, vale a observação.

Outra característica observada em relação ao tipo de locativo referese ao fato de o verbo acarretar um locativo do predicador, ou seja, o locativo é acarretado lexicalmente pelo predicador verbal, daí a rede temática proposta para a classe. Observe a sentença, em (30):

(30) Eu entornei o açúcar na lata.

Temos, em (30), um desencadeador/controle, eu; um afetado/deslocado, $o$ açúcar; e o locativo/afetado, a lata. Para demonstrarmos que o locativo é acarretado pelo predicador verbal e não pela preposição $\mathrm{em}$, sendo assim um argumento do verbo entornar, tomemos como exemplos as sentenças em (31):

(31) a. ?? Na lata, eu entornei o açúcar.

b. ?? Eu entornei o açúcar em $\mathrm{BH}$.

c. Em BH, eu entornei o açúcar na lata.

Quando alteramos a posição do locativo em (31a) para o início da sentença, notamos que tem que haver uma entonação mais marcada, diferentemente do que ocorre em (31c), onde o deslocamento do locativo $B H$ parece mais natural, porque se trata de um locativo do evento. Em (31b), o fato de se ter omitido o locativo do predicador torna a sentença um pouco anômala, pois 
não é possível identificar, especificamente, o lugar no qual aconteceu a ação, visto que em $B H$ é o local em que se deu o evento. Se tomarmos em $B H$ como locativo do predicador, parece-nos que teremos uma interpretação em que a cidade está toda cheia de açúcar.

Outro aspecto observado é o fato de haver uma escolha lexical de certos argumentos pelo predicador e, também, entre os próprios argumentos. Conforme assumimos anteriormente, parece que os argumentos acarretados pelo predicador pertencem ao mesmo campo semântico deste. Veja em (32):

(32) O juiz expulsou o jogador do campo.

Em (32), o desencadeador/controle é o juiz; o afetado/deslocado é o jogador; e o locativo/afetado é o campo. Podemos observar em (32) que há uma rede de relações de sentido entre os argumentos acarretados pelo predicador verbal. Toda a proposição é formada a partir de itens que pertencem ao mesmo campo semântico. Se falarmos que "o juiz expulsou o aluno do campo" ou "o professor expulsou o jogador da sala", parece que o esperado pelo ouvinte é comprometido; não que as sentenças não sejam boas semanticamente, mas parece haver uma quebra de expectativa na interpretação da sentença por parte do ouvinte. Comprove em (33):

? O juiz expulsou o jogador do hospital.

Entre os cento e três verbos que compõem essa classe, podemos ainda citar os seguintes: botar, centrar, amontoar, derrapar, esparramar, plantar, injetar, sentar, mergulhar, rebater, aconchegar, tirar, tombar, acrescentar, trazer, apanhar, afundar, etc.

\subsection{Classe 2: $A\{D(C), \quad A / D e s l$, Trai $\}$ $B\{D(C) / D e s l, \quad A /$ Desl, Trai $\}$}

(34) A mãe desceu o filho do carrinho para o chão.

(35) Maria leva as crianças da casa até a escola.

Nesta classe, ao todo, foram listados trinta e um verbos, mais prototípicos, sendo quatorze da Classe 2-A (exemplo (34)), e dezessete da Classe 2-B 
(exemplo (35)). Aúnica diferença entre as classes A e B é a segunda apresentar um desencadeador deslocado; assim como na Classe 1. Para efeitos da análise das outras propriedades, essa diferença não será relevante. Portanto, fica somente registrada a descrição mais fina dos constituintes da rede temática dos verbos dessa classe. O resto da análise se fará considerando-se uma classe única.

A Classe 2 é formada por verbos que acarretam um desencadeador (controle) (deslocado), um afetado/deslocado e a trajetória que é o movimento expresso pelo predicador. Relembrando, trajetória é o deslocamento do objeto de um ponto A (origem ou fonte) para um ponto B (destino ou alvo) ${ }^{3}$. Nessa classe, a trajetória tem a possibilidade de aparecer explícita na sintaxe, diferentemente da Classe 1:

(36) O artilheiro chutou a bola da lateral para o gol.

Podemos ver que a sentença, em (36), possui um predicado de quatro argumentos: o argumento externo, o artilheiro, é o desencadeador/controle; o argumento interno, a bola é o afetado/deslocado; a lateral, o ponto inicial da trajetória; $o$ gol, o ponto final da trajetória.

Para evidenciar que a trajetória pode ser toda explicitada na sintaxe, podemos mostrar que esses verbos são do tipo accomplishment, ou seja, a ação expressa pelo verbo se desenvolve durante um intervalo $t$, tendo um ponto inicial, um meio e um ponto final. Podemos demonstrar esse fato, utilizando o teste de aspecto, explicitado anteriormente. Observe as sentenças em (37):

(37) a. O artilheiro quase chutou a bola da lateral para o gol.

b. O cavaleiro quase apeou do cavalo.

Quando acrescentamos o item lexical quase, temos uma ambigüidade, pois o desencadeador pode não ter conseguido atingir o gol ou ele pode nem ter iniciado a ação de chutar. Diferentemente, em (37b), o desencadeador/ controle, o cavaleiro, não apeou do cavalo, porque quase apear não apresenta ambigüidade, já que apear é um verbo do tipo achievement.

Também foram aplicados testes de apagamento e deslocamento dos argumentos para comprovar a natureza argumental da rede temática proposta. $\mathrm{O}$ apagamento não se mostrou um teste eficaz para tal comprovação, 
pois, apesar de a classe permitir toda a explicitação da trajetória, ou seja, os pontos inicial e final, também é permitido o apagamento de um dos pontos da trajetória. Entretanto, esse teste revelou uma interessante característica de verbos que têm a possibilidade de expressar toda a trajetória na sintaxe: os dados mostram que o ponto de origem pode ser mais omitido que o de destino. Observe as sentenças em (38) e (39):

(38) a. Mariana arrastou o sofá do canto para o meio da sala.

b. Mariana arrastou o sofá para o meio da sala.

c. * Mariana arrastou o sofá do canto.

(39) a. Ela seguiu o namorado da porta da casa até a praça.

b. Ela seguiu o namorado até a praça.

c.* Ela seguiu o namorado da porta da casa.

A sentenças (a e b) são perfeitamente gramaticais. Entretanto, as sentenças (c) não são aceitas se houver uma leitura de trajetória (somente a leitura de adjunto adnominal é possível, em alguns casos). Esse comportamento aparece na maioria dos verbos dessa classe.

Em relação ao deslocamento dos argumentos, a mudança de pontos da trajetória para o início da sentença não fica muito boa, o que é um indício de que a trajetória também é um locativo do predicador, ou seja, é um acarretamento do predicador verbal. Demonstraremos esse fato, fazendo, em (40), os deslocamentos dos pontos da trajetória e, em (41), o deslocamento de um locativo do evento, acrescentado à mesma sentença (40):

(40) a. Mariana arrastou o sofá do canto para o meio da sala.

b. ?? Do canto, Mariana arrastou o sofá para o meio da sala.

c. ?? Para o meio da sala, Mariana arrastou o sofá do canto.

d. ?? Do canto para o meio da sala, Mariana arrastou o sofá.

(41) a. Mariana arrastou o sofá do canto para o meio da sala, na sua casa.

b. Na sua casa, Mariana arrastou o sofá do canto para o meio da sala.

Fica evidente, com os exemplos (40) e (41), que os pontos inicial e final são argumentos do predicador verbal, segundo a proposta aqui assumida. 
Outros verbos da Classe 2 são: arredar, baldear, abaixar, abrir, remover, rebaixar, carregar, conduzir, mover, seguir, deslocar, etc.

\subsection{Classe 3: $\{D(C) /$ Desl, Loc/A $\}$}

(42) João chegou à faculdade.

$\mathrm{Na}$ Classe 3, foram listados doze verbos, mais prototípicos. Os dados da Classe 3 são bastante interessantes para boa parte desse trabalho, pois é, também, nessa classe que aparece o 'argumento interno preposicionado'. Esse argumento difere daqueles apresentados em Cançado (2003a, 2005), em que se apresentam dados em que há argumentos introduzidos por preposições inerentes e argumentos que marcam alternâncias sintáticas. A autora propõe que preposições que encabeçam o objeto indireto, chamadas de inerentes por não poderem ser tiradas ou trocadas, e preposições que marcam alternância de diátese, como Maria (se) preocupou com a prova, são preposições funcionais, pois o papel temático do argumento que essas preposições encabeçam são atribuídos pelo verbo. É importante observarmos que as preposições que introduzem os argumentos internos preposicionados, como mostrado em (42), são diferentes das apontadas por Cançado; primeiro, porque não são inerentes aos verbos, já que podem ser cambiadas. Veja em (43):

(43) João chegou de/a/em Paris.

Em segundo lugar, elas também não fazem parte de sentenças onde houve mudança da diátese verbal. O verbo chegar acarreta um desencadeador/ controle/deslocado na posição de argumento externo e um locativo/afetado na posição de argumento interno, como mostrado no exemplo (43).

Os dados sugerem que verbos que denotam trajetória, em PB, têm que explicitar o ponto inicial e/ou final dessa trajetória através de uma preposição. Nas outras classes não temos problemas, pois existe um argumento interno que é o objeto deslocado, e a trajetória é sempre expressa por preposições, em posição de adjunção. Entretanto, a diferença básica dessa classe para as duas primeiras é que o objeto deslocado no processo é o próprio desencadeador que vai para a posição de argumento externo. $\mathrm{O}$ argumento interno refere-se 
a um ponto da trajetória, inicial ou final, o locativo/afetado, e, por isso, vem marcado com a preposição, para que esses pontos fiquem explícitos. Portanto, a nossa conclusão é que o ponto da trajetória expresso por verbos desse tipo é um argumento interno, porém é um argumento preposicionado. A natureza dessa preposição também é funcional, como as preposições inerentes e marcadoras de alternância de diátese, pois esses argumentos são acarretados pelo verbo, e não pelas preposições que os encabeçam.

A Classe 3 também é composta de verbos que acarretam a trajetória, mas só aceita a explicitação sintática de um dos pontos dessa trajetória. Se o ponto será inicial ou final vai depender do sentido lexical do predicador verbal:

(44) a. Um homem desconhecido entrou na sala.

b. Ele saiu da escola.

Em (44a), o ponto da trajetória que aparece explícito é o destino; já em (44b), é a origem.

Em geral, os verbos dessa classe são tratados como inacusativos na literatura, porque só expressam o final do processo. Podemos observar isso, aplicando testes que mostram que essas sentenças são consideradas achievements, já que os achievements denotam um evento de momento único. Sentenças, por exemplo, em que aparece a palavra quase acompanhando verbos do tipo achievement não admitem dupla interpretação. Veja em (45) e (46):

(45) As tropas quase partiram para o norte.

(46) Os meninos quase subiram na árvore.

Em (45) e (46), notamos que a utilização da palavra quase significa que as tropas não partiram para o norte e que os meninos não subiram na árvore.

Foram aplicados outros dois testes sintáticos, para evidenciar a natureza argumental da rede temática proposta: o apagamento e o deslocamento dos argumentos. Quanto ao teste de apagar argumentos, vimos que a sentença só aceita uma leitura que tenha um argumento implícito default com o apagamento do argumento locativo/afetado. Por exemplo, se apagarmos o argumento locativo/afetado do verbo chegar, teremos uma interpretação de que o ponto de chegada do movimento é o lugar em que o falante está. Observe em (47): 
(47) a. João chegou.

b. João entrou.

c. João saiu.

Para interpretarmos as sentenças, em (47), associamos o locativo implícito ao lugar onde está o falante da sentença.

O deslocamento dos termos mostra-nos que o deslocamento do locativo do predicador (argumento do verbo) faz com que a sentença fique pior que o deslocamento do locativo do evento. Veja em (48):
a. ? Da escola, João saiu.
b. ? Em casa, João chegou.
c. Em casa, João lê um livro.
d. Na sala, Maria toca piano.

Portanto, podemos concluir que os verbos da Classe 3 são aqueles que só admitem a representação sintática de parte da trajetória; o locativo é acarretado pelo predicador e é afetado; são verbos do tipo achievement, ou seja, verbos de um momento único.

Outros exemplos da classe são: subir, ausentar, comparecer, penetrar, trepar, etc.

\subsection{Classe 4: $\{D(C) / D e s l$, Traj $\}$}

(49) O garoto correu da casa para a rua.

$\mathrm{Na}$ Classe 4, foram listados trinta e quatro verbos, mais prototípicos. A Classe 4 apresenta verbos que acarretam desencadeador/deslocado (controle) e trajetória. Semelhantemente à Classe 3, os verbos da Classe 4 também apresentam argumento interno preposicionado, pois, ao acarretar os pontos inicial e final da trajetória, esses só podem vir introduzidos por preposições, de natureza funcional, como concluído acima. Entretanto, o que vai diferenciar a Classe 4 da Classe 3 é que aos verbos da Classe 4 é permitida toda a explicitação da trajetória:

(50) João andou de uma loja até a outra. 
Em (50), temos João como desencadeador/deslocado, e de uma loja até a outra como pontos inicial e final da trajetória. Se é verdade que João andou, é verdade que ele se deslocou de um ponto A para um ponto B. Portanto, são verbos que podem explicitar toda a trajetória na sintaxe e terão como característica aspectual (aksionsart) ser um accomplishment. Com o exemplo abaixo, vemos que esses verbos apresentam ambigüidade ao utilizarmos a palavra quase:

(51) As crianças quase retornaram da escola para casa.

Vemos que, em (51), o desencadeador/controle/deslocado, as crianças podem tanto ter retornado para casa quanto nem terem iniciado o movimento. Devido à dupla interpretação, podemos concluir, portanto, que o predicador retornar e os outros verbos dessa classe são do tipo accomplishment.

Ainda em relação à natureza do aksionsart, o fato de apagarmos a trajetória de alguns dos verbos dessa classe fará com que o predicador se transforme em uma atividade:

(52) João andou sempre.

A atividade se caracteriza por constituir momentos sucessivos, ou seja, João andou em um momento, depois em outro, e assim sucessivamente. Se colocarmos a expressão em $x$ minutos, que caracteriza um momento único, a sentença fica agramatical; ao contrário da sentença em (53), em que temos um accomplishment:

(53) a. *João andou em duas horas.

b. João andou de uma loja até a outra em duas horas.

Também como na Classe 2, o apagamento do ponto inicial, ou seja, a origem do movimento é preferível ao apagamento do ponto final, o alvo. Veja os dados abaixo:

(54) a. O carro descambou da rua para o rio.

b. * O carro descambou da rua.

c. O carro descambou para o rio. 
(55) a. O exército marchou do quartel até a fronteira.

b. * O exército marchou do quartel.

c. $\mathrm{O}$ exército marchou até a fronteira.

Entretanto, existem alguns verbos dessa classe que apresentam um comportamento um tanto específico em relação ao apagamento de um dos pontos: apagam tanto a origem quanto o alvo:

(56) a. Os soldados retornaram da guerra para seus lares.

b. Os soldados retornaram da guerra.

c. Os soldados retornaram para seus lares.

(57) a. A estudante voltou de Paris para a sua casa.

b. A estudante voltou de Paris.

c. A estudante voltou para sua casa.

Verbos desse tipo são: voltar, retornar, regressar, tornar, volver, fugir, mudar e recuar, e, possivelmente, outros de significação semelhante.

Para comprovarmos a natureza argumental da rede temática proposta, utilizamos novamente o deslocamento dos pontos da trajetória:

(58) a. As aves voaram dali para o telhado.

b. ? Dali para o telhado, as aves voavam.

c. No céu, as aves voavam.

Em (58b), temos a trajetória acarretada pelo predicador e, por isso, o deslocamento desses argumentos parece ser pior do que em (58c), em que temos o locativo acarretado pelo evento no mundo e seu deslocamento parece mais aceitável.

Outros verbos que compõem a Classe 4: saltar, mudar, ir, engatinhar, caminhar, locomover, entre outros.

\subsection{Classe 5: $\{\mathrm{A} /$ Desl, Loc/A $\}$}

(59) O copo caiu do armário.

$\mathrm{Na}$ Classe 5, foram listados apenas nove verbos, mais prototípicos. A Classe 5 é constituída por verbos de movimento que selecionam um ponto 
da trajetória apenas, como ocorre também nas Classes 1 e 3; mas, diferentemente, do que acontece nessas classes, os verbos da Classe 5 acarretam um argumento externo que não desencadeia o movimento, mas somente é afetado por ele. Assim como a Classe 3, esses verbos são, em geral, tratados pela literatura como verbos inacusativos, ou seja, verbos que explicitam sintaticamente somente a parte afetada pelo processo. Por isso, também, nessa classe, teremos uma interpretação aspectual do tipo achievement. Aplicando o teste, temos:

(60) O livro quase escapuliu da minha mão.

O exemplo em (60) somente pode ter a leitura do tipo achievement, ou seja, com o uso do quase só se tem a leitura do evento, como se este nem tivesse se iniciado.

Também temos nessa classe o argumento interno preposicionado, apresentando uma natureza funcional. Isso significa que o argumento interno tem que ser encabeçado por uma preposição, mesmo sendo acarretado pelo predicador verbal, pois é necessário que se marque um dos pontos da trajetória acarretada pelo predicador.

Uma comprovação de que o argumento interno realizado é um locativo do predicador é a menor aceitação do deslocamento desse locativo, em relação a um locativo do evento:

(61) a. O menino apareceu no quarto, naquela casa mal assombrada.

b. ?? No quarto, o menino apareceu naquela casa mal assombrada.

c. Naquela casa mal assombrada, o menino apareceu no quarto.

Ainda, como na Classe 3, se apagarmos o argumento interno, parece haver uma leitura default de que o locativo do predicador só pode ser o lugar em que se encontra o falante da sentença (parece melhor essa interpretação, se usarmos um adjunto localizando o evento temporalmente):

(62) O copo caiu nesse minuto.

(63) O livro escapuliu da minha mão agora.

(64) O menino apareceu de repente.

Os outros verbos listados nesta classe são: escorregar, ruir, surgir, transbordar, escapar, desaguar. 


\subsection{Classe 6: $\{D(C) /$ Desl, Loc/A, (Trai) $\}$}

(65) O alpinista transpôs os Andes do lado oeste para o lado leste.

A Classe 6 é composta por oito verbos, mais prototípicos, que acarretam um desencadeador/controle/ deslocado, um locativo/afetado e, ainda, aceitam uma trajetória como especificação do locativo/afetado, que pode, ou não, aparecer na representação sintática. Essa classe é diferente de todas as outras quanto à sua possibilidade de especificar o locativo/afetado. As outras classes ou apresentam um locativo/afetado ou apresentam uma trajetória. Essa é a única classe que permite que as duas possibilidades ocorram juntas. É óbvio, entretanto, que a trajetória, como especificação do argumento interno, tem que pertencer a um mesmo campo semântico:

(66) a. João atravessou o rio de uma margem até a outra.

b. * João atravessou o rio do andar de cima para baixo.

Também pode ocorrer o apagamento de toda a trajetória, já que esta é apenas uma especificação do locativo/afetado, sem danos para a aceitação da sentença:

(67) O alpinista transpôs os Andes.

Quanto à sua natureza aspectual, esses verbos se comportam como um accomplishment, pois podem expressar todos os pontos da trajetória: o início, o meio e o fim. Ao aplicarmos o teste do quase, comprovamos essa afirmação, visto que se obtém uma dupla leitura. Observe em (68):

(68) Maria quase subiu as escadas da Penha do primeiro até o último degrau.

Na sentença expressa em (68), temos um desencadeador/controle/deslocado, Maria, um locativo/afetado, as escadas da Penha, e os pontos da trajetória, do primeiro até o último degrau. Portanto, se é verdade que Maria quase subiu as escadas da Penha do primeiro até o último degrau, ou é verdade que ela nem começou o movimento, ou que ela o fez até certo ponto, sem atingir o último degrau. Essa ambigüidade nos leva a crer que os predicadores desta 
classe são verbos do tipo accomplishment, pois, diferentemente, dos verbos do tipo achievement, desenvolvem-se num intervalo de tempo que marca o início, o meio e o clímax do movimento.

Em relação à trajetória, os dados da Classe 6 também aceitam mais o apagamento da fonte ou origem que do alvo ou destino, como vimos nas Classes 2 e 4 . Veja que não é possível apagar o ponto final da trajetória:

(69) a. João atravessou o rio de uma margem até a outra.

b. João atravessou o rio até a outra margem.

c. * João atravessou o rio de uma margem.

(70) a. O ciclista cruzou o país do norte até o sul.

b. O ciclista cruzou o país até o sul.

c. * O ciclista cruzou o país do norte.

Outros verbos desta classe são: pular, saltar, escalar, galgar.

\subsection{Verbos sem trajetória explícita: $\{D / C, A / D e s \mid\}$}

(71) O menino envelopou suas figurinhas.

Foram listados alguns verbos, que nós não iremos tratar como uma classe específica por exigir uma análise mais acurada, mas iremos apontálos como exemplos interessantes e objeto de um futuro estudo. Esses verbos acarretam um desencadeador/controle e um afetado (objeto deslocado); entretanto, apesar de se tratar de verbos de movimento, eles não admitem a explicitação da trajetória, nem mesmo de um de seus pontos. Existe a denotação de que o afetado percorre o espaço entre um ponto A e um ponto B; porém, essa trajetória não aparece explícita na estrutura sintática.

A sentença, em (71), é formada por um desencadeador/controle, $o$ menino, e um afetado/deslocado, suas figurinhas. Veja que derivamos da sentença o acarretamento do deslocamento do argumento interno, o afetado/ deslocado: se é verdade que o menino envelopou suas figurinhas, é verdade que o argumento suas figurinhas se desloca de um ponto determinado A (as mãos do menino) para um ponto determinado B (o interior do envelope); entretanto, essa trajetória não está descrita sintaticamente. A idéia do movimento está contida no próprio sentido do item lexical, envelopar, e 
parece que o argumento externo delimita o ponto inicial de uma trajetória e o próprio verbo delimita o ponto final. Veja que, se acrescentarmos o ponto final dessa trajetória a esse tipo de sentença, ela fica redundante:

(72) ?? O menino envelopou suas figurinhas em envelopes.

Como nos casos de verbos com objetos cognatos, esse ponto só será aceito na sintaxe, se for alguma informação mais específica do que a contida no verbo:

(73) O menino envelopou suas figurinhas em envelopes coloridos.

Vejamos alguns outros exemplos desse comportamento:

(74) a. ?? O médico hospitalizou o paciente no hospital.

b. O médico hospitalizou o paciente no melhor hospital da cidade.

(75) a. ??O governo repatriou o soldado para a pátria.

b. O governo repatriou o soldado para a pátria amada.

Outros verbos que têm comportamentos parecidos são: naufragar, semicerrar, repatriar, reerguer, entre outros ${ }^{4}$.

\section{CONCLUSÃO: QUADRO GERAL DAS CLASSES}

Para concluir esta análise, faremos uma comparação geral entre as classes, apontando: a rede temática de cada uma; um exemplo prototípico de cada classe; as propriedades semânticas do aspecto e também da relação entre o campo semântico do verbo e seus argumentos; e as propriedades sintáticas do apagamento de argumentos e deslocamento de argumentos. Assim, o leitor pode ter uma visão comparativa do comportamento sintático e semântico de cada classe, além de ficar mais evidente a motivação que gerou a separação das classes, tal como aqui apresentada:

\section{a.) Classe 1: $A\{D(C), \quad A / \operatorname{Desl}, \operatorname{Loc}(A)\}$ \\ $B\{D(C) /$ Desl, A/Desl, Loc $(A)\}$}


Exemplo: Eu entornei o açúcar na lata.

Propriedade Aspectual: achievement.

Campo Semântico: pede relação entre os argumentos e o verbo.

Apagamento: alguns exemplos possíveis, outros não.

Deslocamento: leitura menos aceitável.

b.) Classe 2: $A\{D(C), \quad A / D e s l$, Traj. $\}$

$B\{D(C) / D e s l, A / D e s l$, Traj. $\}$

Exemplo: O artilheiro chutou a bola da lateral para o gol.

Propriedade Aspectual: accomplishment.

Campo Semântico: pede relação entre os argumentos e o verbo.

Apagamento: preferência para a origem.

Deslocamento: leitura menos aceitável.

c.) Classe 3: $\{\mathrm{D}(\mathrm{C}) / \mathrm{Desl}$, Loc/A $\}$

Exemplo: João chegou à faculdade.

Propriedade Aspectual: achievement.

Campo Semântico: não pede relação entre os argumentos e o verbo. Apagamento: leitura default do lugar do falante.

Deslocamento: leitura menos aceitável.

\section{d.) Classe 4: $\{D(C) /$ Desl, Trai $\}$}

Exemplo: O garoto correu da casa para a rua.

Propriedade Aspectual: accomplishment.

Campo Semântico: pede relação entre os argumentos da trajetória. Apagamento: preferência da origem (embora existam exemplos que apagam os dois pontos, o inicial ou o final).

Deslocamento: leitura menos aceitável.

e.) Classe 5: $\{A / D e s l$, Loc $/ A\}$ 
Exemplo: O copo caiu do armário.

Propriedade Aspectual: achievement.

Campo Semântico: não pede relação entre os argumentos e o verbo. Apagamento: leitura default do lugar do falante.

Deslocamento: leitura menos aceitável.

\section{f.) Classe 6: $\{\mathrm{D}(\mathrm{C}) /$ Desl, Loc/A, (Trai) $\}$}

Exemplo: O alpinista transpôs os Andes do lado oeste para o lado leste. Propriedade Aspectual: accomplishment.

Campo Semântico: pede relação entre a especificação do argumento, a trajetória e o argumento interno.

Apagamento: possível de toda a trajetória; dentro da trajetória, preferência para a origem.

Deslocamento: leitura menos aceitável.

As generalizações que podem ser feitas, a partir desse quadro são:

- o deslocamento dos argumentos locativos do predicador verbal parece ser menos aceitável que o deslocamento de um locativo do evento, em todas as classes;

- quando só se tem um locativo/afetado, tem-se um achievement (classes 1,3 e 5);

- quando se tem a trajetória explícita, tem-se um accomplishment (classes 2, 4 e 6);

- quando se tem uma trajetória, a preferência para o apagamento é do argumento que tem o papel temático de origem (classes 2,4 e 6);

- quando se tem um argumento na posição de objeto que é o deslocado, é preferencial que se tenha uma relação do campo semântico do verbo e seu argumento interno (classes 1 e 2);

- quando se tem um argumento deslocado na posição de argumento externo, e a sentença é um achievement, o apagamento do argumento interno faz gerar uma interpretação default de ser o lugar de onde o falante da sentença está (classes 3 e 5);

- quando a trajetória é a especificação de um locativo/afetado, pode-se apagar toda a trajetória (classe 6). 
Como considerações finais, podemos salientar que a análise feita é uma descrição bem abrangente das propriedades semânticas e sintáticas das classes apresentadas e que parece cobrir uma grande parte dos verbos que denotam trajetória no PB. Evidentemente, nas descrições das classes, pode-se encontrar um exemplo ou outro que não tenha um comportamento totalmente igual ao exemplo prototípico apresentado, o que não invalida o caráter descritivo desta pesquisa. De uma maneira geral, os dados analisados seguiam um determinado padrão e conseguimos classificá-los como pertencentes a uma determinada classe, pela maioria das propriedades apresentadas. Com isso, esperamos ter conseguido apresentar um quadro bem claro de como esses verbos se comportam sintática e semanticamente, além de terem surgido também, no decorrer dessa análise, algumas argumentações de natureza teórica.

\section{NOTAS}

${ }^{1}$ Esses dados se encontram disponíveis no endereço: http://www.letras.ufmg.br/ nupes, no link Teses e Dissertações.

${ }^{2}$ Os parênteses indicam que o controle e o afetado são propriedades optativas, ou seja, existem casos em que elas podem estar presentes, como no exemplo (24) e outros em que essas propriedades não estão presentes, como neste exemplo:

(i) A tempestade submergiu o barco nas águas do mar. (sem controle)

(ii) A costureira centralizou o molde no tecido. (locativo não afetado)

${ }^{3}$ Seguindo a idéia de Jackendoff (1990), vale realçar que trajetória (path) é diferente de percurso (route). No percurso, os pontos inicial e final não são explicitados:

(i) João perambulou pela floresta durante toda a noite.

${ }^{4}$ Existem ainda alguns verbos parecidos com esses que nem mesmo aceitam a especialização do objeto:

(i) ?? Os garotos trocaram figurinhas de um para o outro. 


\section{REFERÊNCIAS BIBLIOGRÁFICAS}

CANÇADO, M. 2003a. Um Estatuto Teórico para os Papéis Temáticos. In: Semântica Formal. MULLER, Ana Lúcia; NEGRÃO, Esmeralda; FOLTRAN, Maria José. (Orgs.) São Paulo: Editora Contexto, p. 95-124.

CANÇADO, M. (Org.) 2003b. Predicação, Relações Semânticas e Papéis Temáticos: Anotações de Carlos Franchi. Revista de Estudos da Linguagem. Belo Horizonte, Faculdade de Letras, UFMG, vol. 11, n. 2.

CANÇADO, M. 2005. Posições Argumentais e Propriedades Semânticas. DELTA, São Paulo, vol. 21, n. 1: 23-56.

CRYSTAL, D. 1988. Dicionário de Lingüística e de Fonética. Tradução de M. C. Pádua Dias. Rio de Janeiro: Jorge Zahar Editor.

DOWTY, D. 1989. On the Semantic Content of the Notion of Thematic Role. In: CHIERQUIA; PARTEE; TURNER. (Eds.) Properties, Types and Meaning. Studies in Linguistic and Philosophy, 2: Semantic Issues, 69-129. Daordrecht: Kluver.

DOWTY, D. 1991. Thematic Proto-Roles and Argument Selection. Language 67: 547-619.

FOLTRAN, M. J. 1999. As Construções de Predicação Secundária no Português doBrasil: Aspectos Sintáticos e Semânticos. Tese (Doutorado) - USP, São Paulo.

FRANCHI, C.; CANÇADO, M. 2003. Teoria Generalizada dos Papéis Temáticos. Revista de Estudos da Linguagem. Belo Horizonte, Faculdade de Letras, UFMG, vol. 11, n. 2.

JACKENDOFF, R. 1990. Semantic Structures. Cambridge (MA): MIT Press. VENDLER, Z. 1967. Linguistics in Philosophy, Ithaca: Cornell University Press. 